\title{
Loss of amplitude of accommodation in pre-presbyopic HIV and AIDS patients under treatment with antiretrovirals
}

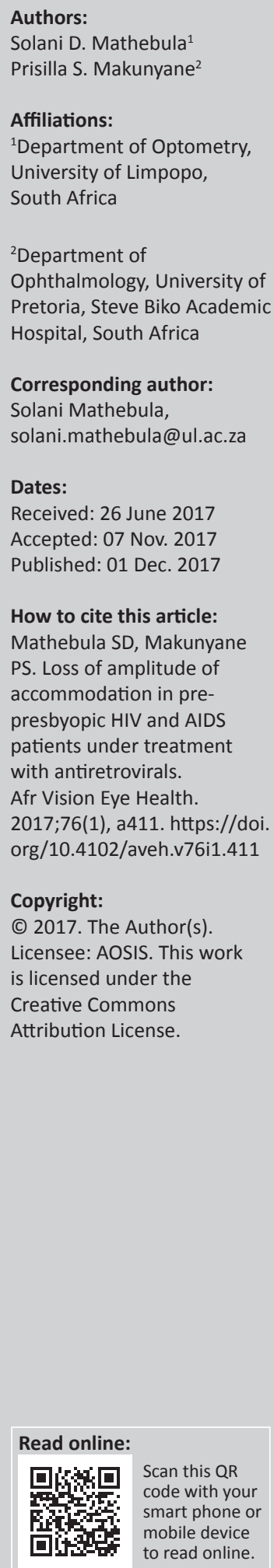

Background: The prevalence of HIV and AIDS is causing an enormous public health burden. Its manifestations spare no organ. Ocular complications are mainly attributed to various opportunistic infections which are directly or indirectly caused by immune deficiency.

Purpose and aim: The purpose of this study was to determine the effect of HIV and AIDS on subjective amplitude of accommodation of patients under treatment with antiretrovirals and then to compare their results to those of control subjects.

Methods: The study took place over a period of 10 months. A quantitative study was carried out on 58 subjects $(29 \pm 5.5$ years $)$ with HIV and AIDS and 35 ( $28.67 \pm 4.6$ years) controls of similar age. Amplitude of accommodation was measured using the subjective Royal Air Force push-up method. The influence of CD4+ cell count was also recorded.

Results: People with HIV and AIDS had lower mean amplitude of accommodation (5.69 $\pm 0.88 \mathrm{D})$ compared to controls $(8.53 \pm 1.2 \mathrm{D})$. The decrease in amplitude of accommodation did not show any correlation with the CD4+ cell count. Lower amplitude of accommodation exists in people living with HIV and AIDS when compared with age-related healthy people.

Conclusion: The results suggest that patients with HIV and AIDS on antiretroviral drugs (ARVs) have reduced amplitude of accommodation and might experience presbyopia earlier in life than participants without HIV and AIDS. The reduced amplitude of accommodation could be the initial presentation of HIV infection before the systemic manifestation. The possible causes could be the direct neuronal infection by HIV-1, ARVs use, pathological changes of the lens and ciliary muscle or the sensory component of the visual system. It is unknown whether the reduced amplitude of accommodation occurred prior to antiretroviral therapy or represents an ongoing injury to the eye and visual system by the HIV.

\section{Introduction}

Since the first report of Pneumocystis carinii pneumonia some 36 years ago or so, the Human Immunodeficiency Virus/Acquired Immunodeficiency Syndrome (HIV and AIDS) has been identified, and has emerged as one of the most challenging infectious diseases of our time. ${ }^{1} \mathrm{HIV}$ and AIDS has reached virtually every corner of the globe, making a profound impact on every aspect of modern society. $2,3,4,5$ In South Africa, HIV was first reported in 1985 and soon cases increased exponentially. Irrespective of the area of specialisation, HIV and AIDS is a concern to all doctors and health care workers.

HIV and AIDS is a multisystem disease $\mathrm{e}^{3}$ that can affect various systems and organs of the body, including the eye (its manifestations spare no organ). The ocular manifestations of HIV and AIDS were first reported in 1982 by Holland et al. ${ }^{6}$ Several reports have shown that $70 \%-80 \%$ of HIV and AIDS patients will suffer optical and non-optical ocular manifestations at any point in time during the course of the disease. ${ }^{7,8,9,10,11}$ The optics and biometry of the eye are also affected in people with HIV and AIDS and blurriness of vision could be the first sign of its presence. ${ }^{6}$

Accommodation is an important feature of the visual system that allows the eye to focus objects placed at different distances. ${ }^{12,13,14,15}$ Accommodation is mediated by the parasympathetic innervation of the ciliary muscle of the eye from the Edinger-Westphal nucleus of the midbrain. The crystalline lens changes its shape in a controlled manner owing to forces applied by the ciliary 
muscle. This crystalline lens is the main determinant of accommodation, and with increasing age it becomes thicker and more curved owing to its continual growth throughout life ${ }^{13,14}$ while the ciliary muscle is the effector of accommodation. The maximum amount of accommodation that can be exerted is called amplitude of accommodation, which decreases with age, leading to presbyopia. ${ }^{13}$ Changes in the crystalline lens and ciliary muscle are central to the development of presbyopia. ${ }^{13}$

Presbyopic patients present clinically with difficulty in nearvision tasks. Around 55 years, little or no amplitude of accommodation remains. ${ }^{13}$ A conference abstract by $\mathrm{Wu}$ et al. ${ }^{16}$ and clinical observations by Westcott et al. ${ }^{17}$ have reported reduced amplitude of accommodation in a small sample of $10 \mathrm{HIV}$ and AIDS patients. From an optical perspective, this leads to the hypothesis that eyes of people with HIV and AIDS act as older eyes in terms of accommodation than those of people of the same age without HIV and AIDS. Hence, the purpose of this study was to test the hypothesis to better understand the loss of amplitude of accommodation accompanying HIV and AIDS. To date we are not aware of a study conducted to provide a quantitative estimate of the reduced amplitude of accommodation across different ages in HIV and AIDS patients. To gain further insight into the reduced amplitude of accommodation, we conducted this case-control study on subjective amplitude of accommodation of HIV and AIDS patients taking antiretroviral treatment (ART) and controls. A review of relevant literature suggests that the association of HIV and AIDS with reduced amplitude of accommodation has received little attention.

\section{Methods}

Outpatient HIV and AIDS patients were invited to participate in this study. All patients and controls gave informed consent prior to agreeing to participate in the study. Measurements were performed on consecutive HIV and AIDS patients receiving ART who volunteered to participate. Age, sex, recent $\mathrm{CD} 4+$ cell count, visual acuity and amplitude of accommodation were recorded. A brief ocular history was also obtained followed by examination of anterior and posterior segments. Subjects were excluded from the study if they demonstrated any type of retinopathy, uveitis, history of ocular surgery and trauma, diabetes, cataract, amblyopia and abnormal anterior segments, and were not currently taking any medication known or suspected to interfere with accommodation. Inclusion criteria were HIV and AIDS patients taking ART, best corrected distance visual acuity of at least $6 / 6$ or better and normal anterior segments and normal pupil sizes. All control subjects were in good physical and ocular health with best corrected distance visual acuity of at least $6 / 6$ or better.

\section{Procedure}

Before the subjective amplitude of accommodation was measured, distance and near visual acuities and subjective refractions were determined and recorded. The subjective amplitudes of accommodation were measured using the Royal Air Force (RAF) ruler under monocular condition. The RAF ruler is well established in clinical practice and research. ${ }^{12,18}$ It is one of the most common and simplest clinical methods to measure amplitude of accommodation and other ocular functions.

The participant's distance refractive correction was placed in the trial frame and the normal room illumination was used. The target, a N5 line of letters, was initially placed at a distance of approximately $40 \mathrm{~cm}$ and moved slowly towards the participant along the ruler. The participants were instructed to keep the letters on the N5 line as clear as possible and to report when they first became blurred and difficult to read. The endpoint was the first slight sustained blur, which was considered to be the point when the target could not be cleared after 2 or $3 \mathrm{~s}$ of viewing. ${ }^{12,18}$ That point was recorded as the amplitude of accommodation in dioptres (D). This was repeated three times and the average of the three measurements was taken. The test was performed monocularly with the fellow eye being occluded. Even though subjective amplitudes of accommodation were measured for both eyes, only the measurements of the right eyes of both HIV and AIDS and controls were used herein for analysis.

\section{Statistical analysis}

After data collection, the data were analysed using the IBM Statistical Package for Social Science (SPSS) version 23. Medians, means and standard deviations were determined. Normality of data was tested using the Kolmogorov-Smirnov test. The differences in subjective amplitude of accommodation between the groups were tested using the $t$-test. The statistical significance was set at $p<0.05$ for all tests.

\section{Ethical considerations}

The study was approved by both the University of Limpopo, Turflop Research Ethics Committee (TREC), and University of Pretoria, Faculty of Health Sciences Research Ethics Committee, and complied with the tenets of the Helsinki Declaration. It took place over a period of 10 months at the ART clinic of Mankweng Hospital, Limpopo Province, South Africa.

\section{Results}

Subjective amplitude of accommodation for the right eyes of $58 \mathrm{HIV}$ and AIDS patients on antiretroviral drugs (ARVs) and 35 matched-age controls were analysed. In the HIV and AIDS group, there were 40 females and 18 males with mean age of $29.93 \pm 5.4$ years. The mean age of the control group was 28.71 \pm 4.6 years. The age range for all the groups was $20-39$ years. The descriptive statistics for the measurements are reported in Table 1. The average amplitude of accommodation for the HIV and AIDS group was 5.69 D while that for the control was 8.53 D. The HIV and AIDS group showed an average 
of 2.84 D below the control group, with a range of 2.52-3.16 D. The independent-sample $t$-test was performed and showed that there was a significant statistical difference between the amplitude of accommodation measured in HIV and AIDS patients and the controls, $p<0.000$.

Figure 1 shows computer-generated box plots (or box-andwhisker plots) of the spread or dispersion of the subjective amplitudes of accommodation. The bold horizontal line in the middle of the plots represents the median (50th percentile) of each distribution. The edges of the box above and below the median are the quartiles (25th percentile below and 75th percentile above). The box itself represents the middlemost 50th of the distribution. The box has 'whiskers' (hence, boxand-whisker), that is, the vertical lines one below the first quartile and one above the 3rd quartile, which represent the distribution of a full set of measurements. The whiskers indicate the smallest and largest measurements in each

TABLE 1: Descriptive statistics of subjective amplitudes of accommodation in dioptres.

\begin{tabular}{lll}
\hline Variable & HIV and AIDS patients & Control group \\
\hline Number of subjects & 58 & 35 \\
Sex: female/male & $40 / 18$ & $20 / 15$ \\
Age & & \\
Mean \pm SD & $29 \pm 5.5$ years & $28.67 \pm 4.6$ years \\
Range & $20-39$ years & $20-38$ years \\
Overall mean amplitude of & $5.69 \pm 0.88 \mathrm{D}$ & $8.53 \pm 1.2 \mathrm{D}$ \\
accommodation & & \\
95\% confidence interval of the & Upper: 5.92 & Upper: 8.94 \\
difference & Lower: 5.46 & Lower: 8.11 \\
Mean amplitude of & Females: $5.83 \pm 0.81 \mathrm{D}$ & Females: $8.33 \pm 1.17 \mathrm{D}$ \\
accommodation according to sex & Males: $5.38 \pm 0.98 \mathrm{D}$ & Males: $9.03 \pm 1.23 \mathrm{D}$ \\
Mean CD4+ cell count & $432.78 \pm 141.9$ cells/ $\mu \mathrm{L}$ & - \\
Range & $220-680$ cells/ $\mu \mathrm{L}$ & - \\
Unaided visual acuity & $6 / 18-6 / 6$ & $6 / 9-6 / 3$ \\
Corrected visual acuity & $6 / 6$ or better & $6 / 6$ or better \\
\hline
\end{tabular}

SD, standard deviation; $\mathrm{D}$, dioptre.

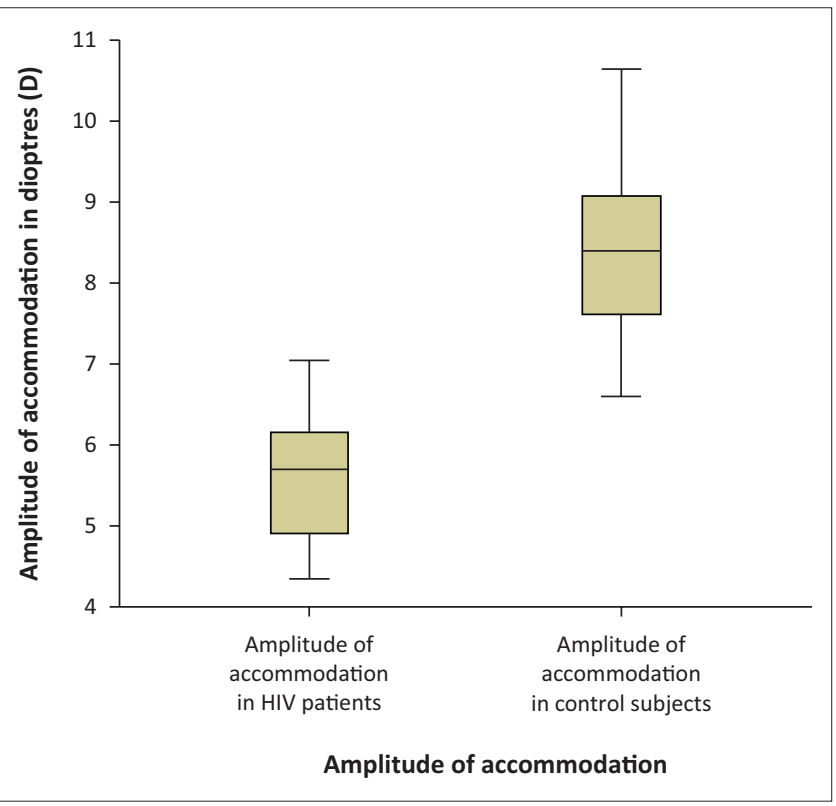

FIGURE 1: Box plots for the subjective amplitudes of accommodation in HIV and AIDS patients and the control group. Each box plot represents the distribution of the measurements concerned. distribution. The box plots showed that the distributions of the subjective amplitudes of accommodation were roughly symmetrical and satisfied the requirements of normality and homogeneity. It can be seen from the plot and Table 1 that the amplitude of accommodation in patients with HIV and AIDS was reduced compared with the controls.

Pearson product-moment correlation coefficients $(r)$ were determined to investigate whether there was a relationship between variables of concern (see Table 2). The $r$ quantifies the strength of the relationship between two variables. The coefficient takes values between -1 and 1 . The negative or minus sign denotes an inverse while a positive quantity denotes a direct relationship. A value of $r$ closer to either 1 or -1 indicates a strong linear relationship while a value closer to 0 indicates a random scatter of the values.

If two variables are highly correlated, it is feasible to graphically depict the relationship on a scatter plot or scatter diagram to predict the value of one (the dependent variable) from the value of the other (independent variable) using the regression model. The value of one variable $(x)$ is used to predict the value of the other variable $(y)$. The straight line on the scatter plot is the regression line. The results obtained with the push-up method in both groups were plotted against age (see Figures 2 and 3). Figure 2 showed a near zero

TABLE 2: Correlation coefficients for the variables in the measurement of subjective amplitudes of accommodation in HIV and AIDS and controls.

\begin{tabular}{lcc}
\hline Paired data & Correlation coefficient $(\boldsymbol{r})$ & Significance $(\boldsymbol{p})$ \\
\hline $\begin{array}{l}\text { Amplitude of accommodation in } \\
\text { HIV and age of HIV subjects }\end{array}$ & -0.141 & 0.321 \\
$\begin{array}{l}\text { Amplitude of accommodation in } \\
\text { HIV and CD4+ cell count }\end{array}$ & 0.046 & 0.731 \\
$\begin{array}{l}\text { Amplitude of accommodation in } \\
\text { control and sex of controls }\end{array}$ & 0.234 & 0.177 \\
$\begin{array}{l}\text { Amplitude of accommodation in } \\
\text { control and age of controls }\end{array}$ & -0.784 & 0.000 \\
$\begin{array}{l}\text { Amplitude of accommodation in } \\
\text { HIV and amplitude of } \\
\text { accommodation in controls }\end{array}$ & 0.077 & 0.660 \\
\hline
\end{tabular}

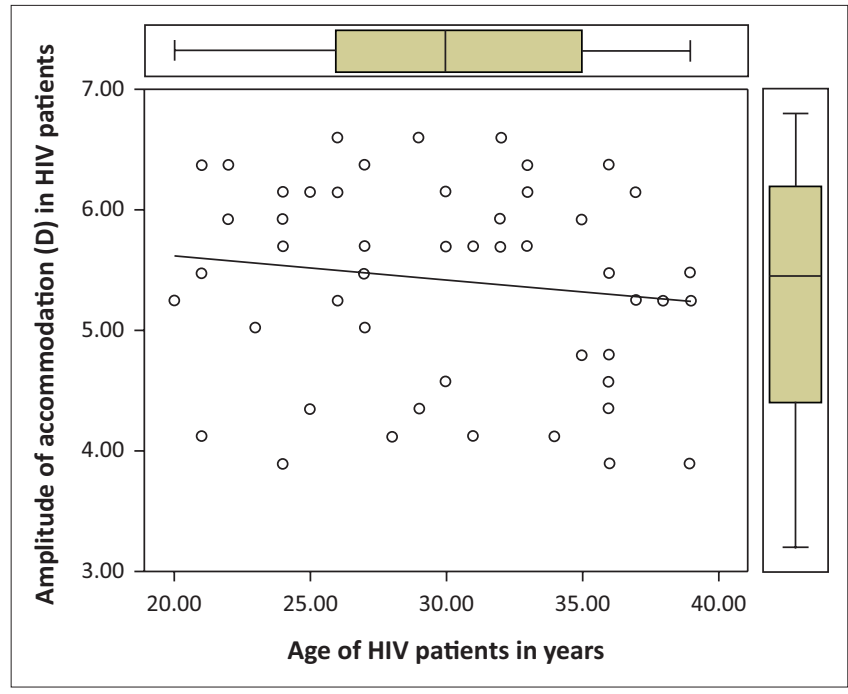

The linear fit is $y=6.4-0.023$ (age of HIV and AIDS patients), $r^{2}=0.02, p=0.29$. There was a poor negative correlation $(r=-0.14)$.

FIGURE 2: Correlation between the amplitude of accommodation in HIV patients and their ages. 


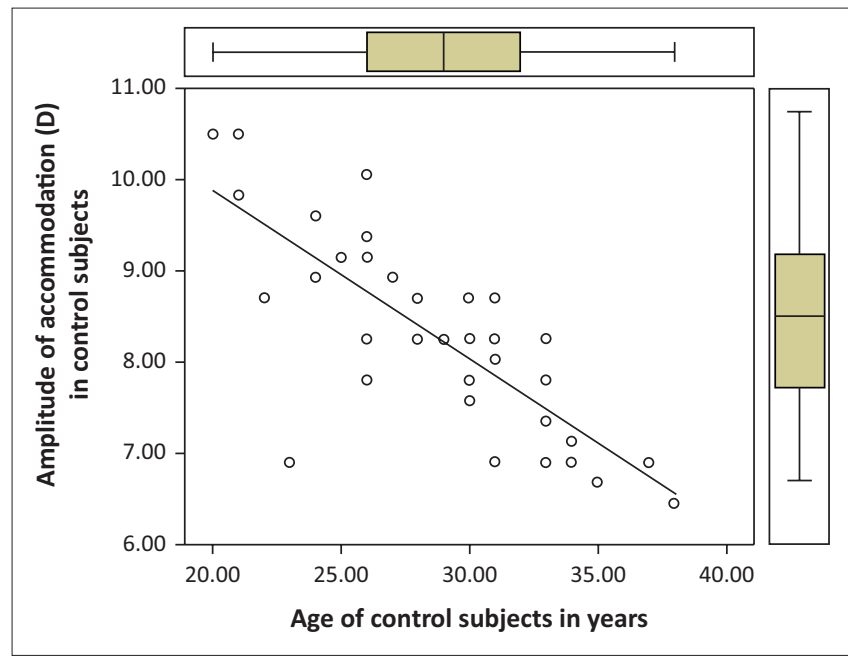

The linear fit is $y=12.8-0.26$ (age: controls), $r^{2}=0.62, p=0.00$. There was a strong negative correlation $(r=0.78)$

FIGURE 3: Correlation between the subjective amplitude of accommodation and age of the control subjects.

correlation, that is, a random scatter of the measurements while Figure 3 showed a statistically significant decrease of subjective amplitude of accommodation with age in the control group.

\section{Discussion}

HIV and AIDS is a global pandemic, with cases reported from every country. The cause of HIV and AIDS is believed to be HIV-1 which belongs to the family of human retroviruses and the subfamily of lentiviruses. ${ }^{19,20}$

This study has found a significantly reduced amplitude of accommodation in patients with HIV and AIDS when compared with age-related limits for normal controls. The premature reduction or loss of amplitude of accommodation is called accommodative insufficiency, which may manifest by development of asthenopia leading to blurring of near visual objects. The results support a previous study by Westcott et al. ${ }^{17}$ who observed in their clinical practice that a significant proportion of their HIV-positive patients complained of accommodative difficulties at ages below that of onset of presbyopia. An English abstract in a German article by Thierfelder et al. ${ }^{21}$ also reported reduced amplitude of accommodation in two-thirds of their HIV patients. Our study did not find any relationship between the reduced amplitude of accommodation and the CD4+ cell count $(r=0.046)$. Also, Wu et al. ${ }^{16}$ did not find a statistically significant correlation between CD4+ cell count and the degree of amplitude of accommodation reduction. However, we did not investigate any relationship between the reduced amplitude of accommodation and the ART combinations and the stage of the HIV infection.

The amplitude of accommodation as a function of age in HIV and AIDS and control subjects are shown in Figures 2 and 3, respectively. There was the expected correlation of age and amplitude in the control group but not in the HIV and AIDS patients. It seems there are considerable differences in the biometry and optics of crystalline lenses between people with and without HIV and AIDS (see Figures 2 and 3). Both the crystalline lens and the ciliary muscle may have reduced accommodation functionality in HIV and AIDS subjects.

The underlying mechanism is not clear but this article would attempt to provide the possible hypothesis of the reduced amplitude of accommodation in HIV and AIDS patients. The blood-ocular barrier is composed of the blood-aqueous barrier and the blood-retinal barrier, which provide protection against microbial invasion and maintain the homeostatic control that underpin the ocular physiology. ${ }^{22,23,24,25}$ The bloodaqueous barrier, formed by the non-pigmented epithelium of the ciliary body and epithelium and endothelium of iris, also contributes to the nutrition and function of the crystalline lens. The blood-retinal barrier, which is similar to the bloodbrain barrier, consists of the inner and outer blood retinal barriers. These two functional barriers play a key role in restricting the movement of blood elements to the intraocular chambers and the control of solute and fluid permeability between the circulating blood and neurons.

Reduced amplitude of accommodation in HIV and AIDS patients may either be because of direct neuronal infection by HIV-1, pathological changes to ciliary muscle or the lens or strength in the sensory component of the visual system. During accommodation, there is an increase in the curvatures of the lens resulting from contraction of the ciliary muscle innervated by the motor nerve. The HIV-1 seems to break the blood-ocular barrier and causes direct or indirect changes to ciliary muscle circulation and parasympathetic neuropathy. ${ }^{26,27,28,29}$ The infected cells secrete Tat which circulates in the blood and enters the ciliary body where it activates several protein kinases. The HIV-1 Tat protein then causes the permeability of the ciliary body and ciliary muscle and activates the inflammatory cells which initiate the cellular release of free radicals, cytokines and growth factors. The HIV-1 gene or protein alters the capacity of the ciliary muscle and leads to deterioration of blood circulation and decreases the activity of the ciliary muscle, resulting in inability of the lens to increase its power. The reduced amplitude of accommodation is because of a loss in ciliary muscle strength, and the weakness that patients with HIV and AIDS suffer could be the source of ciliary muscle weakness, and hence reduced amplitude of accommodation.

In general, the extracellular matrix, called the matrix metalloproteinases (MMPs), is believed to contribute to the alterations of the tight junction protein, which lead to bloodbrain barrier, blood-aqueous barrier and blood-retinal barrier dysfunctions. ${ }^{22}$ So, HIV could cause the alteration of these structures. Other possible contributors to reduced amplitude of accommodation may be ciliary muscle tone, deficits in neural input to the ciliary muscle and adverse changes to zonules or the ions pump. ${ }^{28}$

The introduction of highly active antiretroviral therapy (HAART) has reduced the risk of morbidity and mortality, opportunistic infections and has improved the quality of life 
of HIV and AIDS patients. On the contrary, the widespread use of HAART might increase the prevalence of HIV and AIDS because the survival rate improvement may increase to a greater extent than the decline in transmission. The survival rates are likely to increase the prevalence of infectious and non-infectious ocular complications in HIV and AIDS patients, possibly owing to immune reconstitution. ${ }^{30}$ However, the ARVs do not penetrate the eye and visual system owing to ocular barriers while HIV can make way through these barriers. Treating all HIV-infected persons early enough in the course to prevent progression of immunosuppression, more needs to be done to assure protection of the eye and visual system from HIV injury.

There are reports that found higher detectable HIV viral load in tears and intraocular fluid of patients who are under longterm HAART but have an undetectable plasma viral load. ${ }^{31,32,33,34,35}$ This is because the HIV can make way through the ocular barriers but some ARVs show poor permeability in ocular barriers and are largely excluded. We do not know whether or not the reduced amplitude of accommodation occurred prior to antiretroviral therapy or just represents an ongoing injury to the eye and visual system by the HIV. Ophthalmic clinicians need to be cautious about contact instrumentations during clinical procedures as they can be possible modes of HIV spread. Tears, intraocular fluid and ocular tissues can be reservoirs for HIV.

\section{Limitations of the study}

The subjective push-up method suffers from overestimation of the true amplitude of accommodation owing to the effects of depth of field, accommodative pupil constriction and relative angular magnification as the target distance decreases. Although cycloplegia was not used in this study, it is possible that some younger subjects exerted some accommodation during testing which could affect results of amplitude of accommodation. (The push-up method is subjective; hence, in future studies, objective methods are suggested to measure the objective amplitude of accommodation.) The stages of HIV infection and the dosages of the ART were not recorded. It is possible that the stages of the diseases could affect the measurements likewise the ART. Lack of baseline information on the ophthalmic assessment upon initial diagnosis of HIV infection could be a further limitation of this study.

\section{Conclusion}

This study has showed reduced subjective amplitude of accommodation in patients with HIV and AIDS when compared with age-related controls; however, it remains unknown if the difference can be attributed to the disease process or its treatment. This suggests that HIV and AIDS patients may experience presbyopia earlier in life owing to changes in their ciliary muscles and/or the strength in the sensory component of the visual system than people without HIV and AIDS. Reduced amplitude of accommodation may be the primary or initial manifestation of the diseases, and defective accommodative system may develop in HIV and AIDS patients. The effects of ARVs in the reduced amplitude of accommodation need further investigation as the drugs cannot enter the visual system. Early diagnosis and rehabilitation of such patients with proper corrective lenses may improve their quality of life.

Further studies are needed to investigate possible causes of this reduced amplitude of accommodation in HIV and AIDS patients. This reduced amplitude of accommodation in HIV and AIDS patients may be under-recognised or neglected in these patients, and if not treated may affect their quality of life.

\section{Acknowledgements}

We would like to gratefully acknowledge the study participants without whom this study would have not been a reality. We also acknowledge the staff nurses in the ART and ophthalmic clinics for their assistance during data collection. The authors thank Professor David Goss of Indiana University for helpful suggestions. This paper is based on research support by the South African Medical Research Council to SD Mathebula under South African Medical Research Council (SAMRC) research strengthening and capacity building at selected universities.

\section{Competing interests}

The authors declare that they have no financial or personal relationships which may have inappropriately influenced them in writing this article.

\section{Authors' contributions}

S.D.M. and P.S.M. made equal contributions to the writing of this article.

\section{References}

1. Centre for Disease Control (CDC). Pneumocystis pneumonia-Los Angeles. MMWR Morb Mortal Wkly Rep. 1981;30:250-252.

2. Gallo RC, Montagnier L. The discovery of HIV as the cause of AIDS. N Engl J Med. 2003;349(24):2283-2285. https://doi.org/10.1056/NEJMp038194

3. Jabs DA. AIDS and ophthalmology in 2004. Arch Ophthalmol. 2004;122(7): 1040-1042. https://doi.org/10.1001/archopht.122.7.1040

4. Martin SS, Peter S. HIV and the eye; a global perspective. Expert Rev Ophthalmol. 2009;4(2):113-114. https://doi.org/10.1586/eop.09.2

5. Sepkowitz KA. AIDS - The first 20 years. N Engl J Med. 2001;344(23):1764-1772. https://doi.org/10.1056/NEJM200106073442306

6. Holland GN, Gotlieb MS, Yee RD, Schanker HM, Pettit TH. Ocular disorders associated with a new severe acquired cellular immunodeficiency syndrome associated with a new severe acquired cellular immunodeficiency syndrome. 90127-1

7. Jabs DA. Ocular manifestation of HIV infection. Trans Am Ophthalmol Soc. 1995; $93: 623-683$.

8. Holland GN, Pepose JS, Petit TH, Gotlieb MS, Yee RD, Foos RY. Acquired immune deficiency syndrome: Ocular manifestation. Ophthalmology. 1983;90(8):859-873. https://doi.org/10.1016/\$0161-6420(83)80009-8

9. Fauci AS. Twenty-five years of HIV and AIDS. Science. 2006;313(5786):409. https://doi.org/10.1126/science.1131993

10. Bekele S, Gelaw Y, Tessema F. Ocular manifestation of HIV and AIDS and correlation with CD4+ cell count among adult HIV and AIDS patients in Jimma town, Ethiopia; a cross sectional study. BMC Ophthalmol. 2013;13:20. https://doi.org/10.1186/ 1471-2415-13-10

11. Moraes HV. Ocular manifestation of HIV and AIDS. Curr Opin Ophthalmol. 2002;13(6):397-403. https://doi.org/10.1097/00055735-200212000-00010 
12. Mathebula SD, Kekana TM, Ledwaba MM, Mushwana DN, Malope NE. A comparison in university students of the amplitude of accommodation comparison in university students of the amplitude of accommo
determined subjectively. Afr Vision Eye Health. 2016;75(1):Article 358.

13. Wold JE, Hu A, Chen S, Glasser A. Subjective and objective measurement of human accommodative amplitude. J Cataract Refract Surg. 2003;29(10):1878-1888. https://doi.org/10.1016/S0886-3350(03)00667-9

14. Lisa LA, Glasser A. Accommodation measurements in a prepresbyopic and presbyopic population. J Cataract Refract Surg. 2004;30(7):1435-1444. https:// doi.org/10.1016/j.jcrs.2003.12.045

15. Momeni-Moghaddam H, Kundart J, Askarizadeh F. Comparing measuremen techniques of accommodative amplitude. Indian J Ophthalmol. 2014;62(6): 683-687. https://doi.org/10.4103/0301-4738.126990

16. Wu P, Williams JG, Phillips BJ, Khanna A, Friedlander SM, Goldstein DA. Loss of accommodative amplitude in AIDS patients. Invest Ophthalmol Vis Sci. 1997;38(Suppl):1101.

17. Westcott MC, Ward M, Mitchell SM. Failure of accommodation in patients with HIV infection. Eye. 2001;15:474-478. https://doi.org/10.1038/eye.2001.158

18. Atchison DA, Capper EJ, McCabe KL. Critical subjective measurement of the amplitude of accommodation. Optom Vis Sci. 1994;71(11):699-706. https://doi. org/10.1097/00006324-199411000-00005

19. Simon V, Ho DD, Karim QA. HIV and AIDS epidemiology, pathogenesis, prevention and treatment. Lancet. 2006;368(9534):489-504. https://doi.org/10.1016/ S0140-6736(06)69157-5

20. Malessa R, Angelink MW, Diener HC. Dysfunction of visual pathways in HIV-1 infection J Neurol Sci. 1995;130(1):82-87. https://doi.org/10.1016/0022-510X(95)00002-J

21. Thierfelder S, Mellinghoff-Kreplin G, Hasenfratz G. Clinical studies of reduced accommodation in patients with HIV-1 infection. Kiln Monatsbl Augenheilkd. 1999;204(6):523-526. (Articlein German). https://doi.org/10.1055/s-2008-1045477

22. Abbott NJ, Patabendige AA, Dolman DE, Yusof SR, Begley DJ. Structure and function of the blood-brain barrier. Neurobiol Dis. 2010;37(1):13-25. https://doi. org/10.1016/j.nbd.2009.07.030

23. Cunha-Vaz JG. The blood-ocular barriers. Doc Ophthalmol. 1979;23(5):279-296. https://doi.org/10.1016/0039-6257(79)90158-9
24. Occhiutto ML, Freitas FR, Maranhao RC, Costa VP. Breakdown of the ocular barrier as a strategy for the systemic use of nanosystems. Pharmaceutics. 2012;4(2) 252-275. https://doi.org/10.3390/pharmaceutics4020252

25. Muh-Shy C, Hou PK, Tong-Yuan T, Lin BJ. Blood-ocular barriers. Tzu Chi Med J. 2008;20(1):25-34. https://doi.org/10.1016/S1016-3190(08)60004-X

26. Che $X$, Fan XQ, Wang ZL. Mechanism of blood-retinal barrier breakdown induced by HIV-1. Exp Ther Med. 2014;7(4):768-772. https://doi.org/10.3892/etm. 2014.1521

27. Che $X$, He F, Deng Y, et al. HIV-1 Tat-mediated apoptosis in human blood-retinal barrier-associated cells. PLoS One. 2014;9(4):Article ID e95420. https://doi. org/10.1371/journal.pone.0095420

28. Gadsby DC. Ion channels versus ion pumps: The principal difference, in principle. Nat Rev Mol Cell Bio. 2009;10(5):344-352. https://doi.org/10.1038/nrm2668

29. Chatterjee N, Callen S, Seigel GM, Buch SJ. HIV-1 Tat-mediated neurotoxicity in retinal cells. J Neuroimmune Pharmacol. 2011;6(3):399-408. https://doi.org/ 10.1007/s11481-011-9257-8

30. Bosamiya SS. The immune reconstitution inflammatory syndrome. Indian J Dermatol. 2011;56(5):476-479. https://doi.org/10.4103/0019-5154.87114

31. Han Y, Wu N, Zhu W, Li Y, Zuo L. Detection of HIV-1 viruses in tears of patients even under long-term HAART. AIDS. 2011;25(15):1925-1927. https://doi.org/10.1097/ QAD.0b013e32834b3578

32. Pathanapitoon K, Riemens A, Kongyai N, Sirirungsi W, Leechanachai P. Intraocula and plasma HIV-1 RNA loads and HIV uveitis. AIDS. 2011;25(1):81-86. https://doi. org/10.1097/QAD.0b013e328340fe91

33. Minuesa G, Huber-Ruano I, Pastor-Anglada M. Drug uptake transporters in antiretroviral therapy. Pharmacol Ther. 2011;132(3):268-279. https://doi.org/ 10.1016/j.pharmthera.2011.06.007

34. Urtti A. Challenges and obstacles of ocular pharmacokinetics and drug delivery. Adv Drug Deliv Rev. 2006;58(11):1131-1135. https://doi.org/10.1016/j.addr. 2006.07.027

35. Tom M, Hosoya K. The role of blood-ocular barrier transporters in retinal drug disposition. Exp Opin Drug Metab Toxicol. 2010;6(9):1111-1124. https://doi.org/ 10.1517/17425255.2010.486401 